\title{
Development and Research Status of ZA27 Zinc Alloy
}

\author{
Wang Heng, Ma Yiming \\ Suzhou Xiangguan Alloy Research Institute Ltd., Suzhou, China
}

Email address:

hitwangheng@163.com (Wang Heng)

\section{To cite this article:}

Wang Heng, Ma Yiming. Development and Research Status of ZA27 Zinc Alloy. International Journal of Materials Science and Applications. Vol. 10, No. 5, 2021, pp. 124-128. doi: 10.11648/j.ijmsa.20211005.15

Received: September 10, 2021; Accepted: October 15, 2021; Published: October 21, 2021

\begin{abstract}
In recent years, due to the rapid development of industry, the manufacturing processing quality was required to be higher and higher day by day, which made a major breakthrough in the research of metal materials. A series of new technologies and processes have been developed. The application and promotion of these technologies and processes have greatly improved the technical level of the non-ferrous metal industry, especially in the field of zinc alloy. ZA27 zinc alloy received extensive attention during this period. ZA27 zinc alloy is widely used in automobiles, construction, household appliances, ships, light industry, machinery, batteries and other industries due to its excellent wear resistance, friction reduction and mechanical properties. For these reasons, ZA27 zinc alloy has become a good substitutive material for copper alloy. In this paper, according to the research history and current situation of ZA27 zinc alloy around the world, the effects of different adding elements and the characteristics of different processes were comparatively analyzed, and summarized the progress at home and abroad. At the same time, this paper pointed out the problems existing in the development and production of ZA27 zinc alloy, which provided the basis for the development of ZA27 zinc alloy in the future.
\end{abstract}

Keywords: ZA27, Zinc Alloy, Trace Elements, Treatment Technology, Mechanical Property

\section{Introduction}

The International Lead Zinc Research Organization (ILZRO) was founded in London in 1958. The purpose of the organization is to maintain and expand the existing Lead and Zinc market through the development, funding and management of product development projects, and to collect closely related information that affects the environmental and health in the process of production and use of metals [1]. In 1959, the International Lead and Zinc Research Organization developed a research and development plan, making ILZRO-12 casting Zinc Alloy as the focus of this plan [2].

In the mid-1970s, the Nornda Mines Limited research and development institution in Canada investigated the technical data of ILZRO-12 casting Zinc Alloy and cooperated with the Eastern Company in America successively developed three kinds of Zinc Alloy ZA8, ZA12 and ZA27. The alloy composition of ZA27 zinc alloy was shown in Table 1. ZA27 zinc alloy has attracted a wide spread attention since its appearance. It not only has high wear resistance, stable mechanical properties and excellent energy saving characteristics, but also can be widely used in the die casting industry, bearing industry, etc., especially it has partially replaced brass, cast iron and ductile iron as structural materials, it also develops rapidly in the mold industry [3].

Table 1. Chemical Composition of ZA27 Zinc Alloy.

\begin{tabular}{llllllll}
\hline \multirow{2}{*}{ Brand } & \multicolumn{2}{l}{ Chemical composition \% } & \multicolumn{5}{c}{ Impurity $\leq \%$} \\
\cline { 2 - 7 } & Zn & Al & Cu & Mg & Fe & Pb & Cd \\
\hline ZA27 & Residual & $25.5-28.0$ & $2.0-2.5$ & $0.012-0.020$ & 0.072 & 0.005 & 0.005 \\
\hline
\end{tabular}

The use of ZA27 zinc alloy in China started in the late 1970s. It was reported that in order to reduce costs ZA27 zinc alloy was used as sliding bearing instead of tin bronze in Anshan Steel Industry. The direct economic benefit of the project was 250,000 Yuan per year. Jiangsu Hai 'an Heavy Shearing Machine Factory also used ZA27 zinc alloy as sliding bearing instead of tin bronze, the economic cost of this project reduced to 28.26 percent of the previous. Since 1990 , 
many universities in domestic participated in the research on ZA27 zinc alloy. For example, Jiangsu University of Technology has studied the relationship between Si element and the wear resistance of ZA27 zinc alloy [4], Gansu University of Technology has studied the microstructure of ZA27 zinc alloy [5], Guangxi University has studied the impact resistance of ZA27 zinc alloy [6], and University of Science and Technology Beijing has studied the application of ZA27 zinc alloy as a biodegradable material, etc. [7]. Because of the wide application of ZA27 zinc alloy, in order to improve its performance and reduce its shortcomings, many research institutions have done a lot of research. This paper makes a review of the research results, and provides theoretical support for the development of ZA27 zinc alloy.

\section{Trace Elements Research}

\subsection{Al Element}

Al element has the highest percentage as trace element in ZA27 zinc alloy, which determines the type and quantity of primary phase and the number of eutectics. So Al element determines the hardness, tensile strength and casting defects of the alloy. It is found that when there is no $\mathrm{Cu}$ element in the alloy, when the content of $\mathrm{Al}$ element is between 6 percent and 10 percent, with the increase of $\mathrm{Al}$ element content, the hardness and tensile strength of the alloy increase obviously. In the same way, when the content of Al element is between 22 percent and 30 percent, with the increase of $\mathrm{Al}$ element content, the hardness and tensile strength of the alloy show a linear increase. The elongation of the alloy also increases with the increase of $\mathrm{Al}$ element content. When the $\mathrm{Al}$ element content is 26 percent, the elongation of the alloy can reach the maximum value. When the $\mathrm{Al}$ element content is more than 26 percent, the elongation of the alloy decreases slightly. When there is $\mathrm{Cu}$ element in the alloy, and its content is 2.5 percent, the hardness and tensile strength of the alloy increase with the increase of $\mathrm{Al}$ element content. When the content of $\mathrm{Al}$ element is more than 27 percent, the tensile strength of the alloy remains almost unchanged. When the content of $\mathrm{Cu}$ element is 5 percent no matter how much the content of $\mathrm{Al}$ element, the alloy becomes a brittle material with very low elongation. At the same time, the increase of $\mathrm{Al}$ element content will also lead to segregation phenomenon [8].

\subsection{Cu Element}

$\mathrm{Cu}$ element has the second highest percentage as trace element in ZA27 zinc alloy, the effect of it is strengthening. This strengthening effect shows in three aspects: the first is solid solution strengthening, that is, $\mathrm{Cu}$ element has a certain solid solubility in $\mathrm{Zn}-\mathrm{Al}$ alloy; the second is to form intermetallic compound $\varepsilon$ phase $\mathrm{CuZn}_{4}$ to be strengthened; the third is to reduce the eutectoid transformation speed, that is, to reduce phase transformation speed, so make the alloy maintain strength. The maximum solid solubility of $\mathrm{Cu}$ element in ZA27 zinc alloy is 1.3 percent, and the solubility of it at room temperature is 0.8 percent. If the $\mathrm{Cu}$ element content more than this solubility value, it will precipitate as $\varepsilon$ phase $\mathrm{CuZn}_{4}$ and disperse on the matrix. With the increase of $\mathrm{Cu}$ element content, $\varepsilon$ phase $\mathrm{CuZn}_{4}$ in alloy microstructure increases gradually. When $\mathrm{Cu}$ element content is 4 percent, the network-like distribution can be observed in alloy microstructure. It is shown that the $\varepsilon$ phase $\mathrm{CuZn}_{4}$ can hinder the movement of dislocations during the deformation of the alloy, thus improving the tensile strength of the alloy. Here is a description of $\varepsilon$ phase $\mathrm{CuZn}_{4}$. It can hinder the movement of dislocations during the deformation of the alloy, and therefore the tensile strength of the alloy is improved. But when the $\mathrm{Cu}$ element content is more than 2.5 percent, this phenomenon disappears, and on the contrary, the tensile strength and elongation of the alloy appear in the trend of downward, even when $\mathrm{Cu}$ element content is 4 percent, the network-like distribution makes the alloy more brittleness, which has the opposite effect. So many scholars have done accurate research on $\mathrm{Cu}$ element content and finally defined it as 1.25 percent. When $\mathrm{Cu}$ element content is more than 1.25 percent, brittle phase gradually appears at the grain boundary of alloy, and when it is less than 1.25 percent, solid solution strengthening is not enough. Therefore, 1.25 percent of $\mathrm{Cu}$ element content is the key technical data and should be strictly controlled. Many zinc alloy manufacturing enterprises also found that in the heat treatment process of ZA27 zinc alloy, when the $\mathrm{Cu}$ element content is controlled to 1.25 percent, the process is stable after several verifications, can effectively prevent the eutectoid transformation and size instability [9].

\subsection{Mg Element}

$\mathrm{Mg}$ element has the third highest percentage as trace element in ZA27 zinc alloy, the effect of it is to prevent intergranular corrosion. The content of $\mathrm{Mg}$ element usually is between 0.012 percent and 0.02 percent, so $\mathrm{Mg}$ has little effect on the microstructure of the alloy. When the content of $\mathrm{Mg}$ element is less than 0.01 percent, the tensile strength increases with the increase of $\mathrm{Mg}$ element content, but the elongation appears to decrease trend. When the content of $\mathrm{Mg}$ element is less than 0.01 percent, the tensile strength and elongation basically keep unchanged. The test shows that the tensile strength and elongation of the alloy are basically the same when 0.01 percent $\mathrm{Mg}$ is added to the alloy compared with the addition of 2 percent $\mathrm{Cu}$. Therefore, it is proved that $\mathrm{Mg}$ element has the same strengthening effect as $\mathrm{Cu}$ element. But the content of $\mathrm{Mg}$ element should not be too high, because when it is more than 0.02 percent, the hot tearing susceptibility of the alloy increases [10].

\subsection{Other Elements}

\subsubsection{Mn Element}

Mn element as transition element exists in ZA27 zinc alloy as an intermetallic compound, most of it is at the grain boundary of the alloy, and a small part runs through the grain. The effect of Mn element in the alloy is to increase friction properties. The addition of Mn element can significantly increase the hardness of the alloy, makes tensile strength to 
change slightly, and keeps the elongation between 1.8 percent and 3.2 percent. Mn element can improve the wear resistance of the alloy. The main reason is that the $\mathrm{Mn}$ element is distributed in the grain boundary and it is a hard brittle phase, which can cause stress concentration and increase hardness. At the same time, the Mn element at the grain boundary can refine the grain. After grain refinement, there are more channels in the grain boundary, so make the alloy more porosity and less plasticity. In addition, the test shows that the tensile strength and hardness are significantly improved with $\mathrm{Mn}$ element addition at 120 degrees centigrade. This is because Mn element as transition element can rearrange the atoms and increase the recrystallization temperature. At the same time, $\mathrm{Mn}$ at the grain boundary can hinder the diffusion of atoms and improve the mechanical properties of the alloy [11].

\subsubsection{Rare Earth Elements}

Rare earth La series elements with large atomic radius and active chemical properties. The dendrite crystals of ZA27 zinc alloy decreased after adding rare earth elements, showing that rare earth elements have the effect of grain refinement [12]. After grain refinement, the dispersion degree of particles in the alloy increases and the distribution tends to be uniform, so the wear resistance of the alloy is also improved [13]. The wear resistance is improved with the increase of rare earth content of ZA27 zinc alloy which is used for manufacturing bearings. When the content of rare earth elements is 0.3 percent, the bearing wear increases obviously, this effect is by hard rare earth [14]. Rare earth compounds are intermetallic compounds, and the Fe element contained in them is a kind of impurity element. The research shows that when the content of mixed rare earth elements in the alloy increases, the $\mathrm{Fe}$ element content decreases significantly. This shows that rare earth compounds can obtain Fe and resist the effect of Fe [15].

\subsection{Impurity Elements}

\subsubsection{Fe Element}

Fe element is usually mixed in the ZA27 zinc alloy products, thus affecting the quality of products. The research shows that even if the content of the Fe element as an impurity element is very low, iron-rich intermetallic compounds (the content of the Fe element is more than 20 percent) also will be formed in the alloy. Most of the microstructure of this compound is needle-shaped, and the organization of it is hard and brittle. The binding force between the compound and the alloy matrix is weak, resulting in stress concentration, and then appears microcracks, which deteriorate the mechanical properties of ZA27 zinc alloy. Therefore, the content of the Fe element as an impurity element in the alloy must be strictly controlled to avoid or reduce the formation of acicular iron-rich phase [16].

\subsubsection{Pb, Cd, Sn Elements}

$\mathrm{Pb}, \mathrm{Cd}$ and $\mathrm{Sn}$ elements are all impurity elements in ZA27 zinc alloy. Even if their contents are very low, they will also affect the alloy. These three elements do not dissolve in $\mathrm{Zn}$, and are dispersed at the grain boundary, increasing the probability of intergranular corrosion, and reducing the mechanical properties of the alloy to produce microcracks [17].

\section{Research on Treatment Process}

\subsection{Alloying Process}

Different metal elements were added to ZA27 zinc alloy for alloying treatment, and the obtained properties were different. If the $\mathrm{Li}$ element is added to the alloy, the tensile strength of the alloy can increase by 3.1 percent [18]. The addition of the Si element can produce hard particles in ZA27 zinc alloy and form the microstructure with hard soft particles. The wear resistance of this microstructure increases, and there is an optimum proportion of the Si element [19].

\subsection{Modification Process}

Adding different modifiers to get different properties of ZA27 zinc alloy. Such as adding sodium salt to Zn-27Al-Si can change the growth mode of Si crystal. But the nucleation of Si crystal cannot be controlled. With the increase of sodium salt content, the microstructure of $\mathrm{Si}$ phase in the alloy changes from tabular to spherical. The impact toughness increases by 65 percent, the tensile strength increases by 40 percent, and the elongation increases by 145 percent [20]. Metamorphic treatment of Ti salt and Zr salt can significantly reduce the supercooling degree of primary phase precipitation in ZA27 zinc alloy. The nucleation rate is increased and the probability of segregation is reduced. At the same time, the peritectic reaction occurs when Ti salt and $\mathrm{Zr}$ salt are added to the alloy, so the primary phase will precipitate and nucleation will occur many times [21]. After metamorphic treatment of ZA27 zinc alloy by rare earth Ce element, the distribution of each phase in the internal microstructure of the alloy is more uniform, the friction coefficient is significantly reduced, and the wear resistance is significantly increased. The tensile strength can reach $400 \mathrm{MPa}$, and the diffraction rate can reach 3 percent [22]. After metamorphic treatment of ZA27 zinc alloy with Ti salt and B salt, the chemical reaction occurs in the alloy to form high melting point compounds, and the microstructure changes from coarse dendrites to fine dendrites Then in the process of heat treatment, the globular structure is obtained [23]. The composite modifier can refine the grain size of ZA27 zinc alloy. The microstructure observation shows that the coarse dendritic crystal is changed into fine flower crystal, and the phase composition is evenly distributed The tensile strength of the alloy increases by 10 percent, the elongation increases by 7 percent, the friction coefficient decreases by 23.9 percent, and the wear rate decreases by 45.9 percent, but the damping property is obviously improved [24].

\subsection{Heat Treatment Process}

ZA27 zinc alloy can use the heat treatment process to adjust the mechanical properties of alloy casting and obtain stable microstructure, so as to keep the dimensional stability. ZA27 zinc alloy can be aged at 100 degrees centigrade. Amplitude 
modulation decomposition reaction can occur in the alloy during aging treatment. This reaction will generate zinc-poor zone and zinc-rich zone, and the zinc-rich zone forms the $\mathrm{Nm}$ phase. The main factor for the formation of this phase is crystal stacking fault [25].

\subsection{Deformation Process}

The microstructure and mechanical properties of ZA27 zinc alloy can be significantly improved by the deformation process. Research shows that the comprehensive performance of the rolled ZA27 zinc alloy is better than the extrusion alloy. The alloy is affected by the extrusion temperature during extrusion. When the extrusion temperature is high, the tensile strength of the alloy is high and the extend rate is low. When the extrusion temperature is low, the tensile strength of the alloy is low and the diffraction rate is high. The extrusion alloy can be aged at a later stage to obtain better mechanical properties [26]. After extrusion, the tensile strength of as-cast ZA27 zinc alloy can be increased to $460 \mathrm{MPa}$, the extend rate can reach 3 percent, and the Brinell hardness can reach 125 . The life of the nut for press made of this material can be doubled [27].

\subsection{External Magnetic Field Process}

Ideal microstructure of ZA27 zinc alloy can be obtained by external field agitation. Research shows that ZA27 zinc alloy ingots without dendrites were successfully prepared with high rotating magnetic field intensity and good stirring effect. The reason for the formation of this microstructure is that under the action of selected magnetic field, the coarse dendrites in the alloy are broken, the new phases are evenly distributed, and the refinement effect of primary phase is obvious [28]. The fine grain structure of ZA27 zinc alloy can be obtained by electromagnetic stirring during solidification. The lower the stirring speed is, the more developed the grain branching is. The main reason is that the electromagnetic stirring increases the cooling rate and obtains the ideal microstructure, which is better than that of the alloy without electromagnetic stirring [29].

\subsection{Neural Network Process}

With the development of computer technology, the model of casting process parameters and mechanical properties of ZA27 zinc alloy was established by using neural network. The influence of process parameters on mechanical properties was analyzed, and the potential problems of the alloy were predicted. Shenyang University of Technology conducted in-depth research in this aspect. They established the squeeze casting process and mechanical properties model of ZA27 zinc alloy, and predicted the mechanical properties. The results were the same as the actual results. Through this model, the optimal extrusion process parameters were obtained that extrusion pressure was $67 \mathrm{MPa}$, holding time was 30 seconds, and pouring temperature was 580 degrees centigrade. This parameter was consistent with the test [30].

\subsection{Composite Material Process}

The wear resistance and high temperature mechanical properties of ZA27 zinc alloy can be enhanced by ceramic particles. The results show that $\mathrm{SiC}$ particles can be dispersed in ZA27 matrix and can be used as the core part of $\mathrm{CuZn}_{4}$ crystallization. When the mass fraction of $\mathrm{SiC}$ is 30 percent, the wear resistance of the alloy can be increased by 125 times [31].

\subsection{Composite Physical Field Process (the Latest Process)}

The physical properties of ZA27 zinc alloy can be improved to a certain extent in a single physical field (pulse magnetic field, ultrasonic, mechanical vibration). When the composite physical field is formed in three physical lengths, the tensile strength can be increased by 27.8 percent, the extension rate can be increased by 74.5 percent, the friction coefficient can be reduced by 17.5 percent, and the corrosion rate can be reduced by 35.7 percent [32].

\section{Conclusion}

In summary, ZA27 zinc alloy has attracted more and more attention due to its low manufacturing cost, low melting energy consumption and excellent mechanical properties. At the same time, the zinc industry in our country has developed rapidly in recent years, and has become a big country of zinc production and consumption in the world. The available reserves of zinc resources in our country led the world. The development trend of ZA27 zinc alloy is:

(1) Optimizing the composition of trace elements in ZA27 zinc alloy, improving production technology and reducing production cost.

(2) Developing advanced ZA27 zinc alloy production process to improve mechanical properties.

(3) Vigorously researching and advancing the development of ZA27 zinc alloy in the direction of wear resistance, corrosion resistance and high strength.

\section{References}

[1] G. Li, H. Y, Y. Z, et al. Challenges in the use of zinc and its alloys as biodegradable metals: Perspective from biomechanical compatibility [J]. Acta Biomaterialia, 2019, 1 (97): 23-45.

[2] B. Yang, L. T. Xia. Investigation development of zinc aluminium alloys $[\mathrm{J}]$. Research studies on foundry equipment, 2007, 5: 30-34.

[3] S. Gao, L. T. Xia, N. Liu, et al. Effect of Bi on structure and properties of ZA27 alloy [J]. Foundry, 2008, 11 (57): $1205-1210$.

[4] C. H. Zhang, S. C. Sun, X. H. Yan, et al. Effects of adding Si as alloy element on wear resistance of ZA27 alloy [J]. China foundry machinery and technology, 2001, 6: 26-28.

[5] T. J. Chen, Y. Hao, J Sun, et al. Microstructure of casting ZA27 alloy [J]. The Chinese journal of nonferrous metals, 2002, 12 (2): 294-299. 
[6] J. Y. Si, J. M. Zeng, H. Gu. Study on elevated temperature impact properties of ZA27 alloy [J]. Foundry technology, 2005, 26 (3): 233-236.

[7] J. S, T. K, K. L, et al. Effects of steel type and sandblasting pretreatment on the solid-liquid compound casting characteristics of zinc-coated steel/aluminum bimetals [J]. Journal of Alloys and Compounds, 2019, 25 (778): 170-185.

[8] Y. W. Zhang. Research progress and application of cast zinc alloy $[\mathrm{J}]$. Heilongjiang Science and Technology Information, 2011, 29: 33.

[9] D. X. Yang, C. Z. Gao, J. P Xie, et al. Effects of $\mathrm{Cu}$ on the microstructure and properties of $\mathrm{Zn}-\mathrm{Al}$ alloy [J]. Foundry technology, 2010, 31 (11): 1448-1451.

[10] Y. L, H. L, H. J. Effects of heat treatment on microstructure and mechanical properties of ZA27 alloy [J]. Transactions of Nonferrous Metals Society of China, 2013, 3 (23): 642-649.

[11] Y. H. Lu, P. Zhao, H. X. Shen. Effect of Mn and Ni alloying on microstructures and mechanical properties of ZA27 alloy [J]. The Chinese journal of nonferrous metals, 2005, 15 (12): 1960-1967.

[12] W. J. Feng, J. Xing. New zinc base wear resistant alloy [J]. Mechanical engineer, 1998, 3: 59-60.

[13] H. Y. Xiang, B. K. Gong, H. Y. Ma, et al. Influence on rare earth elements on wear-resistance of high strength zinc base alloy [J]. Materials for mechanical engineering, 1996, 20 (1): 30-32.

[14] H. F. Zhao, F. L. Zhang, P. L. Zhao. Wear-resistance performance of ZA27 alloy reinforced by rare earth compounds [J]. Journal of the Chinese rare earths society, 1999, 19 (3): 227-230.

[15] Y. H. Dou, Y. Liu, F. Xu, et al. Effect of Fe on microstructure and mechanical properties of ZA27 alloy [J]. Materials science and engineering of powder metallurgy, 2012, 17 (3): 309-314.

[16] Q. L. Zhu, Y. Xia, J. J. Chen, et al. Analysis on inclusions in squeezing casting ZA27 alloy [J]. Foundry, 2016, 25 (2): 158-161.

[17] G. L. Liu, L. Li, R. D. Li. Grain boundary segregation of impurity elements and its effect on corrosion resistance in ZA27 alloy [J]. Journal of Shenyang university of technology, 2005, 27 (4): 381-384.

[18] D. H. Su. Effect of $\mathrm{Li}$ on mechanical properties at high temperature for ZA27 Alloy [J]. Special-cast and Non-ferrous Alloys, 1998, 6: 26-27.

[19] A. M. Li, Q. L. Yang, X. Wu. A study of silicon and rare earth elements for the Pattern of Their Influence Upon ZA27 alloys Mechanical Properties [J]. Journal of Jiaozuo institute of technology, 1997, 16 (4): 17-22.

[20] F. Y. Han, H. F. Zhao, Y. X. Mao, et al. The effect of nodium modifier on the microstructure and properties of $\mathrm{Zn}-27 \mathrm{Al}-\mathrm{Si}$
Alloy [J]. Journal of Taiyuan university of technology, 2001, 32 (3): $282-283$.

[21] P. J. Hou, F. Ni, R. Long, et al. Study on mechanism of Ti and $\mathrm{Zr}$ modification of high aluminum ZA alloy [J]. Research studies on foundry equipment, 2003, 1: 12-15.

[22] X. L. Fu, Y. P. Liu. Effect of Ce on the structure and property of ZA27 alloy [J]. Journal of southeast university, 1994, 24 (4): 125-127.

[23] G. J. Xu, S. Lu, T. J Chen, et al. Effects of B-Ti on structural evolution of semi-solid ZA27 alloy [J]. Journal of Gansu university of technology, 2000, 26 (1): 19-22.

[24] Y. Y. Tan. The Effect of compound modificator on structure and Properties of ZA27 Alloy [J]. Journal of Nanjing university of science and technology, 2002, 26 (5): 547-551.

[25] K. F. Wang. Phase formation during aging of ZA27 alloy at $100^{\circ} \mathrm{C}[\mathrm{J}]$. Journal of Jiaozuo institute of technology, 2000, 19 (1): 70-72.

[26] A. J, M. B, J. K, et al. A new approach to plastic deformation of biodegradable zinc alloy with magnesium and its effect on microstructure and mechanical properties [J]. Materials Letters, 2018, 15 (211): 58-61.

[27] D. C. Li, Y. S. Li, F. X. Zhao, et al. Extruding work of high strength casting zinc-based alloy ZA-27 [J]. Material science and technology, 1996, 4 (2): 92-95.

[28] P. Yu, B. R. Wu, Z. Q. Li, et al. Influence of Rotating Electromagnetic Field on the Structure for ZA-27Alloy [J]. Special-cast and Non-ferrous Alloys, 2002, S1: 52-57.

[29] G. J. Liu, K. Zhang, J. X. Zhang, et al. Microstructure and properties of stir-cast ZA27 alloy [J]. Special-cast and Non-ferrous Alloys, 2000, 1: 10-13.

[30] G. L. Liu, R. D. Li. Application of Neural Network on ZA27 Alloy Squeezing Casting Technology [J]. Foundry technology, 2003, 24 (3): 204-205.

[31] J. P. Xie, Z. G. Yue, A. Q. Wang, et al. Microstructure characteristics of interface and wear resistance of SiCp/ZA27 composites [J]. Special-cast and Non-ferrous Alloys, 2005, 25 (10): 638-640.

[32] L. Zhang. Effect of physical field on solidified structure and mechanical properties of ZA27 alloy [D]. Nanchang Hangkong university, A dissertation submitted for the degree of master on material processing engineering, 2018: 53-81.

\section{Biography}

Wang Heng (1979-), male, was born in Changchun city, Jilin Province, doctor, senior engineer, main research direction: zinc alloy theory and molding process. 